\title{
Founder Generation
}

National Cancer Institute

\section{Source}

National Cancer Institute. Founder Generation. NCI Thesaurus. Code C19642.

The first population of an organism species in a location, from which all members of the current population have descended. 